
\title{
$\begin{array}{ll}\text { Research Square } & \begin{array}{l}\text { Preprints are preliminary reports that have not undergone peer review. } \\ \text { They should not be considered conclusive, used to inform clinical practice, } \\ \text { or referenced by the media as validated information. }\end{array}\end{array}$
}

\section{The Combination of Demineralized Bone Matrix and Platelet Rich Plasma Used for The Treatment of Long Bone non-unions: Preliminary Data of a Case Series}

\section{Wei Nie}

Lianyungang 2nd People's Hospital

Jiaqing Cao

Shanghai 6th Peoples Hospital Affiliated to Shanghai Jiaotong University

Wei Wang

Shanghai 6th People's Hospital Affiliated to Shanghai Jiaotong University

\section{Yanjie Guo}

Shanghai 6th Peoples Hospital Affiliated to Shanghai Jiaotong University

\section{Chi Zhang}

Shanghai 6th Peoples Hospital Affiliated to Shanghai Jiaotong University

Weitao Jia

Shanghai 6th Peoples Hospital Affiliated to Shanghai Jiaotong University

Xiaolin Li ( $\square$ lixiaolinshly@163.com)

Shanghai 6th Peoples Hospital Affiliated to Shanghai Jiaotong University School of Medicine

\section{Research article}

Keywords: Demineralized bone matrix (DBM), Platelet rich plasma (PRP), Bone non-unions, Surgical treatment.

Posted Date: May 4th, 2021

DOI: https://doi.org/10.21203/rs.3.rs-482094/v1

License: (9) (7) This work is licensed under a Creative Commons Attribution 4.0 International License. Read Full License 


\section{Abstract}

Background: Although a variety of bone graft substitutes have been introduced into the treatment of bone non-unions, results from current clinical evidences are various and contradicting. This paper presents our experience and the outcomes about the combination of demineralized bone matrix (DBM) and platelet rich plasma (PRP) used as a bone graft substitute in the surgical treatment of long bone non-unions.

Methods: Data of this retrospective study was reviewed and collected from a consecutive case series involving 16 patients who had a long bone non-union and treated in our department from October 2018 to May 2019. DMB and PRP were applied as a bone defect filler during the index operation. Patients' demographics, postoperative complications and the result of bone union were evaluated.

Results: The postoperative drainage exceeding 48 hours were demonstrated in 6 patients, but all removed within 7 days. Immediate postoperative complications were noted in 3 patients. Two of them developed incision exudation and delayed incision healing (exceed 2 weeks) and was cured with a course of local wound care. No graft rejection, heterotopic ossification or other complications were noted. Bony union was identified clinically and radiographically in 15 of the 16 patients, with a mean time of 7.5 months.

Conclusions: The present study found low incidence of postoperative complications and satisfactory bony healing rate could be achieved in the treatment of long bone non-unions augmented with the combination of DBM and PRP. Although these findings might indicate the promising future of this treatment protocol, larger and higher quality studies should also be executed to assess its routine use.

\section{Background}

With a prevalence estimated to be $5 \%-10 \%$ in long bones [1], the non-union is a disabling disease characterized by the cessation of bone regeneration and the failure of fracture healing. Treatment of non-unions is highly individualized, long lasting and burdensome, and normally requires a dramatic and effective utilization of resources [2, 3]. Autografting is considered as the mainstay of strategy for the management of non-union since the autogenous bone is equipped with the essential elements required in bone regeneration in term of osteoconductivity, osteoinductivity and osteogenesis, as well as the lack of immunogenicity. But the limited supply and donor site morbidities might restrict the application of autogenous bone and led surgeons into an increasing desire of seeking for other options [5]. A variety of biomaterials substitutes, which are available in various forms and large quantities, have been introduced, such as including bone marrow aspirate, allografts, bone substitute materials and biological factors. Although attractive, these novel substitutes have yielded inconsistent results when they were used in clinical settings, either combined or alone $[6,7,8]$.

Among these substitutes, PRP is plasma fraction available from peripheral blood containing higher platelet concentration and considerable amounts of growth factors which are responsible for cellular proliferation, matrix formation, and the collagen synthesis [9]. It has been shown to promote bone repair and soft tissue maturation in many clinical situations [10]. But when used independently, PRP does not produce the desired stimulatory response and provides little benefit for bone tissue repair if a large volume of bone defect exists $[6,8,11]$. Demineralized bone matrix (DBM) is a decalcified allogeneic bone tissue which still preserves collagen, non-collagen proteins, small percentage of growth factors and cellular debris [12]. The plasticity enables DBM to be suitable for filling and repairing bone defects [6]. However, when it was used for the treatment of non-unions, the results were not so encouraging for its' high incidences of complications and low healing rate (approximately $65 \%-84 \%)[13,14]$.

In the present study, the combination of DBM and PRP was applied as a bone graft substitute in the treatment of long bone non-unions. DMB was selected for its osteoconductive and osteoinductive effects based on its physical framework and some bioactive substances, which is lacked in PRP. The characteristic of DBM allows it can be applied in reconstruction of bone defects and could be mixed with various other materials, such as normal saline, antibiotics solution, autograft, allograft, bone marrow aspirate, whole blood or platelet concentrate [7]. PRP has been shown to significantly reinforce the osteoinductivity of DBM when used as an adjuvant without thrombin activation [15]. It can also evoke active responses in promoting the repair of the soft tissue, thus decreasing the related compolications and optimizing the biological environment for bone regeneration. So theoretically, the application of DBM and PRP together might reinforce the healing of bone non-unions than when they were used independently [15]. However, only few animal studies have evaluated the efficacy of the combination of DBM and PRP as a bone substitute and even less articles reported clinical outcomes when it used in the treatment of bone non-unions [16]. We therefore initiated this treatment protocol in which we used the combination of DBM and PRP as a bone graft material to evaluate the outcomes of this combination in in the treatment of long bone non-unions.

\section{Methods}

\section{Patients Demographics}

Data was reviewed and analyzed from the patients who were diagnosed with a bone non-union and underwent our treatment protocol in the trauma center of Shanghai sixth people's hospital from October 2018 to May 2019. Patients with pathological fractures, osteonosus, cancers, immune disorders, thrombocytopenia, platelet dysfunction, large bone defects exceeding $5 \mathrm{~cm}$ of diameter, infectious non-unions, and hypertrophic non-unions without any previous therapeutic intervention (e.g., dynamization, exchange nailing) were excluded from this protocol. This study was performed according to the standards of the Declaration of Helsinki. Patient consents to the treatment protocol were obtained accordingly.

Finally, data from a total of 7 males and 9 females with mean age of 41.2 years (ranging from 28 years to 61 years) was evaluated retrospectively in this study, and 3 cases (accounting for 18.8\%) had a history of a previous open fracture. Six of them underwent more than one prior surgical interventions. Hypertension and diabetes were identified in 5 patients and had been controlled effectively. Causes of injury, localizations of non-union site, types of nonunion and other details of the patients' demographics were tabulated in Table 1. 
Table 1

Patients Demographics

\begin{tabular}{|c|c|c|c|c|c|c|c|c|c|c|c|}
\hline $\begin{array}{l}\text { No. of } \\
\text { patients }\end{array}$ & Sex & $\begin{array}{l}\text { Age } \\
\text { (year) }\end{array}$ & $\begin{array}{l}\text { Affected } \\
\text { side }\end{array}$ & $\begin{array}{l}\text { Causes of } \\
\text { injury }\end{array}$ & $\begin{array}{l}\text { Previous } \\
\text { Open } \\
\text { fracture }\end{array}$ & $\begin{array}{l}\text { Number } \\
\text { of } \\
\text { previous } \\
\text { surgeries }\end{array}$ & $\begin{array}{l}\text { Location of } \\
\text { nonunion } \\
\text { site }\end{array}$ & $\begin{array}{l}\text { Types of } \\
\text { non-union }\end{array}$ & $\begin{array}{l}\text { Initial } \\
\text { hardware }\end{array}$ & $\begin{array}{l}\text { Chronic } \\
\text { disease }\end{array}$ & $\begin{array}{l}\text { Duration } \\
\text { of non- } \\
\text { union }\end{array}$ \\
\hline 1 & $\mathrm{~F}$ & 46 & $\mathrm{~L}$ & $\begin{array}{l}\text { Traffic } \\
\text { accident }\end{array}$ & & 2 & $\begin{array}{l}\text { Femoral } \\
\text { supracondyle }\end{array}$ & Atrophic & plate & hypertension & 18 \\
\hline 2 & $\mathrm{~F}$ & 47 & $\mathrm{~L}$ & $\begin{array}{l}\text { Traffic } \\
\text { accident }\end{array}$ & & 1 & $\begin{array}{l}\text { Tibial } \\
\text { proximal } \\
\text { segment }\end{array}$ & Oligotrophic & plate & & 24 \\
\hline 3 & M & 43 & $\mathrm{R}$ & Fall & Y & 4 & $\begin{array}{l}\text { Tibial mid- } \\
\text { shaft }\end{array}$ & Oligotrophic & plate & & 16 \\
\hline 4 & $\mathrm{~F}$ & 61 & $\mathrm{~L}$ & $\begin{array}{l}\text { machinery } \\
\text { accidents }\end{array}$ & & 1 & $\begin{array}{l}\text { radial mid- } \\
\text { shaft }\end{array}$ & Oligotrophic & plate & $\begin{array}{l}\text { hypertension, } \\
\text { diabetes }\end{array}$ & 18 \\
\hline 5 & M & 38 & $\mathrm{R}$ & Fall & & 2 & $\begin{array}{l}\text { Femoral mid- } \\
\text { shaft }\end{array}$ & Oligotrophic & plate & & 16 \\
\hline 6 & $\mathrm{~F}$ & 36 & $\mathrm{R}$ & $\begin{array}{l}\text { Traffic } \\
\text { accident }\end{array}$ & Y & 2 & $\begin{array}{l}\text { Tibial mid- } \\
\text { shaft }\end{array}$ & Atrophic & plate & & 9 \\
\hline 7 & M & 32 & $\mathrm{~L}$ & Trip & & 1 & $\begin{array}{l}\text { Clavicular } \\
\text { mid-shaft }\end{array}$ & Oligotrophic & plate & & 18 \\
\hline 8 & $\mathrm{~F}$ & 29 & $\mathrm{~L}$ & $\begin{array}{l}\text { Sport } \\
\text { injury }\end{array}$ & & 1 & $\begin{array}{l}\text { Humeral mid- } \\
\text { shaft }\end{array}$ & Oligotrophic & $\begin{array}{l}\text { intramedullary } \\
\text { nail }\end{array}$ & & 12 \\
\hline 9 & $\mathrm{~F}$ & 32 & $\mathrm{R}$ & $\begin{array}{l}\text { Traffic } \\
\text { accident }\end{array}$ & $\mathrm{Y}$ & 2 & $\begin{array}{l}\text { Tibial mid- } \\
\text { shaft }\end{array}$ & Atrophic & plate & & 20 \\
\hline 10 & $\mathrm{~F}$ & 56 & $\mathrm{R}$ & Fall & & 1 & $\begin{array}{l}\text { Femoral mid- } \\
\text { shaft }\end{array}$ & Oligotrophic & plate & $\begin{array}{l}\text { hypertension, } \\
\text { diabetes }\end{array}$ & 14 \\
\hline 11 & $M$ & 28 & $\mathrm{~L}$ & Trip & & 1 & $\begin{array}{l}\text { Clavicular } \\
\text { mid-shaft }\end{array}$ & Oligotrophic & plate & & 15 \\
\hline 12 & $M$ & 31 & $\mathrm{R}$ & Fall & Y & 1 & $\begin{array}{l}\text { femoral } \\
\text { supracondyle }\end{array}$ & Oligotrophic & plate & & 15 \\
\hline 13 & $M$ & 31 & $\mathrm{~L}$ & $\begin{array}{l}\text { Traffic } \\
\text { accident }\end{array}$ & & 1 & $\begin{array}{l}\text { Tibial mid- } \\
\text { shaft }\end{array}$ & Oligotrophic & $\begin{array}{l}\text { intramedullary } \\
\text { nail }\end{array}$ & & 12 \\
\hline 14 & $\mathrm{~F}$ & 56 & $\mathrm{R}$ & trip & & 1 & $\begin{array}{l}\text { proximal } \\
\text { humerus }\end{array}$ & Oligotrophic & plate & diabetes & 20 \\
\hline 15 & $M$ & 41 & $\mathrm{R}$ & $\begin{array}{l}\text { Traffic } \\
\text { accident }\end{array}$ & Y & 2 & $\begin{array}{l}\text { Tibial mid- } \\
\text { shaft }\end{array}$ & Oligotrophic & plate & & 12 \\
\hline 16 & $\mathrm{~F}$ & 52 & $\mathrm{R}$ & $\begin{array}{l}\text { Sport } \\
\text { injury }\end{array}$ & & 1 & $\begin{array}{l}\text { tibial distal } \\
\text { segment }\end{array}$ & Oligotrophic & plate & hypertension & 16 \\
\hline
\end{tabular}

\section{Surgical Procedures}

Non-union was defined as a fracture that not consolidate for a minimum of 9 months without signs of healing for at least 3 months [17], and patients were assessed by radiological appearances (e.g., x-ray, CT, PET-CT), clinical symptoms (e.g., deformity, abnormal activities, infection) and laboratory targets (e.g., white blood cell count, erythrocyte sedimentation rate, C-reactive protein) to identify if a bone infection or an osteonosus exists.

The index surgeries were performed by the same surgical team. After anesthesia, $50 \mathrm{ml}$ of autogenous blood was drawn from peripheral vein and was isolated by two-step centrifugation for the preparation of PRP $(5 \mathrm{ml})$. To avoid devascularization, the periosteum or soft tissues surrounding the non-union site was carefully protected when exposing. Radically debridement of intervening scar tissue between the non-union site and re-open of medullary canals were performed to allow rapid neovascularization and migration of osteogenic cells. The initial hardware was not removed routinely unless they were loosened or there were requirements for debridement, fixation revision or deformity correction. The bone defects caused by debridement was then filled with the paste mixed by DBM putty (Allomatrix, Wright Medical Technology, Inc. Memphis, TN, USA) and PRP at a ratio of 5:1. In patients with a big size of bone defect, allogeneic bone was used for volume augmentation if necessary, and the amount was determined by the size of the defect and the experience of surgeons (Fig. 1). An additional plate would be implanted depending on the demand of mechanical stability. After the placement of a suction drain, standard wound closure and pressure dressing were performed.

\section{Postoperative Management And Follow-up}

All patients were treated with perioperative antibiotic prophylaxis and were informed to quit smoking. Low-molecular weight heparin was given for 2 weeks for patients undergoing the lower extremity surgery. Anteroposterior and lateral position X-ray films were taken within 3 days postoperatively. Normally, the suction 
drain was kept for 2 days and was removed if the daily drainage volume was less than $30 \mathrm{ml} / 24 \mathrm{~h}$. Otherwise, the suction drain would be persisted. However, this practice has been changed in 1 patient, his drain was removed on postoperative day 7 even though the last daily drainage volume was more than $45 \mathrm{ml}$. Passive and active range-of-motion without weight-bearing were encouraged for early rehabilitation within the first 4 weeks, and then weight-bearing and strengthening exercises were recommended depending on radiological findings. Patients were followed up at monthly intervals postoperatively for radiographic and clinical assessment of bony union, which was defined as the presence of bridging callus formation on at least 3 out of 4 cortices in two different planes and the ability to painless weight-bearing.

\section{Outcome Measures And Statistics}

Outcomes including the drainage time, postoperative complications and the time of bony union were reviewed from medical records and follow up data and were was summarized by descriptive statistics using SPSS 22.0 (Chicago, IL, USA). Postoperative complications include incision exudation, delayed wound healing or long-term disunion, superficial or deep infections, and graft rejection. Functional recovery was not assessed because there is a lack of a unified criterion when the affected limbs and localizations of non-union site were different between patients.

\section{Results}

Details of the surgical treatment protocol for each patient were listed in Table 2. The bone defect sizes varied between patients and allogeneic bone was added for augmentation in 5 cases (Table 2). There were 6 of 16 patients whose postoperative drainage persisted beyond 48 hours. In 5 patients, the suction drain was removed within 4 days (Fig. 2). Only in 1 patient (case 15) the drainage was kept for 7 days and was removed even though there was still a daily drainage volume more than $45 \mathrm{ml}$. But no positive symptoms or result of bacterial culture indicating a superficial or deep infection were found.

Table 2

Surgical protocol and postoperative outcomes

\begin{tabular}{|ll|}
\hline & Numbers of cases \\
\hline Bone grafting materials & 11 \\
\hline DMB + PRP & 5 \\
\hline DMB + PRP + allograft & \\
\hline Immediate postoperative complications & 2 \\
\hline Exudation (and delayed incision healing) & 2 \\
\hline Subcutaneous hematoma & 1 \\
\hline Recurrence of bone non-union & 1 \\
\hline
\end{tabular}

Incision exudation and delayed incision healing (exceed 2 weeks) were observed in 2 patients (case 6, 15), one of which was the same patients with 7-day postoperative drainage. They were finally healed after a 3-week course of local wound care including devitalized tissue removal and hydrogel dressing. Subcutaneous hematoma was detected in 1 patient (case 13) after the removal of the suction drain and was cured with percutaneous aspiration and pressure dressing (Table 2). There was no infection, graft rejection, heterotopic ossification or any other complications related to surgeries had been noted, and no one need an additional surgical intervention.

During the follow-up period (ranging from 12 months to 20 months; average 15.4 months), in nearly half of the patients, formation of bony callus appeared on radiographs within 4 months after grafting operations. Whilst, obvious graft absorption at the grafting area was also observed in many patients, mainly within 6 months postoperatively. Fifteen patients demonstrated postoperative clinical union with painless lifting or weight bearing and achieved bony union on radiographical evaluation. However, the distribution of bony healing time was rather scattered, ranging from 3 months to 14 months (mean time 7.5 months) (Fig. 3). Persistent non-union was observed in 1 patient (case 12) at his last visit (16 months postoperatively), in whose X-ray showed the appearance of screw loosening, sclerosis and atrophy at fracture sites and no signs of callus formation. He refused further surgical intervention and could not be available for follow-up after that time point. Despite that, he was still included in this study since the data form him was sufficient for analyses.

\section{Discussion}

The present study demonstrated promising preliminary results in the surgical management of uninfected long bone non-unions with the combination of DBM and PRP used as a bone graft substitute. Initially, this treatment protocol was mainly applied as a salvage for patients who were unwilling to accept an additional harvesting surgery or who had limited availability of autogenous bone due to the history of several previous harvesting surgeries. In this series, the combination of DBM and PRP acted as a safe and effective bone graft substitute as the incidences of local or systemic complications was relatively low, and bony union was achieved in 15 out of 16 patients at the end of follow-up. In addition, comparing with autogenous or allogenous bone, the combination of DBM and PRP exhibited a superior capability of cavity packing as it can be made into various shapes according to the filling part. Besides, it could be concluded that the surgical time, as well as multiple associated complications, would be reduced as there is no need for an additional procedure of an autogenous bone harvesting.

Ziran and colleges identified significant incidences of prolonged drainage, postoperative complications and failure of healing (46\%) following with the application of DBM for patients with non-unions [13]. However, in view of too many patients with a history of previous infection in their study, the authors 
inferred that the inadequately treated bone infection might be a main contributor to the occurrences of postoperative complications and the failure of bony healing. They also surmised that a compromised tissue bed might be another possible reason for the development of subcutaneous hematoma and postoperative infections [13]. Encouraging results were found in Hierholzer's study which retrospectively analyzed 78 patients with non-unions of humeral shaft fractures. The time to union and healing rate in the DBM-augmentation group was comparable to those of the autograft-augmentation group. The authors emphasized that the careful and appropriate operative procedures might play an important role in ensuring the success of their treatment protocol [18].

Based upon the experiences from these studies, multiple active measures were taken in our clinical practice, including comprehensive examinations and perioperative antibiotic coverage to monitor and prevent infections, careful and radical surgical debridement, minimal injury to the surrounding soft tissues, adequate postoperative drainage, and rigid fixation of the non-union sites, all of which were of great benefits for preventing potential complications and facilitating bone regeneration. Concerning the poor physical stability of the DBM, a crucial principle in our operation was the complete coverage to bone graft materials with periosteum or other surrounding soft tissues so that it could provide a protection to the integrity of the graft material and a reconstruct the biological environment for bone regeneration. Benefit from these measures, we encountered relatively low incidence of local or systemic complications in this series.

A finding of the present study is that we noticed most of the patients with prolonged drainage duration and incision-related complications have poor quality of local soft tissue (due to a previous history of open fracture). It might indicate that use of the DBM and PRR couldn't be regarded as a significant independent risk factor to the increased postoperative complications.

Still another important observation was that obvious radiolucent area, without bone proliferation or even with bone absorption, appeared on radiographs in many patients. Only some tiny radiopaque bone fragments were visible in the graft area, which were believed to be left over from the surgical intervention and decalcified bone debris of the DBM. That might mislead surgeons into having a suspicion of the recurrence of bone non-union. The exact mechanism of this phenomenon is difficult to know. It was probably caused by the excellent absorbability of DBM and a slow process of bone proliferation at the non-union site. In this series, the healing time was various between patients and excessed 9 months in several patients. Since we initially had no data on the time necessary for bony healing under this situation, hence the observation time would be prolonged and were mainly determined by the radiographical appearance in which there were signs of progressive bone formation or bony bridge in 3 consecutive months.

Although satisfactory outcomes were obtained in this series, several limitations were identified but difficult to avoided. Due to the absence of comparison groups and the small simple size, the clinical benefits of the using the combination of DBM and PRP instead of other bone graft materials couldn't be verified with convincing evidences. Whilst, some clinical variables, such as the defect size and non-union sites, were not standardized.

\section{Conclusions}

Our experience and preliminary clinical data based on this study suggest that, if properly administered, the combination of DBM and PRP could serve as a safe bone graft substitute in clinical practice for non-union, especially for patients with limited availability of autogenous bone or patients with contraindication for an additional harvesting surgery. Due to the limitations of the present study, further rigorous researches, randomized controlled trials or otherwise, are still indicated for the investigation on its routine use.

\section{Abbreviations}

DBM; demineralized bone matrix; PRP:platelet rich plasma; CT:computed tomography; PET:positron emission tomography.

\section{Declarations}

\section{Ethics approval and consent to participate}

This was a retrospective study and it just collected the clinical information of patients without interference with the outcomes of patients. The personal privacy of patients was protected. Surgeries procedures and the biological materials used in this study complied the requirements of our country. No formal ethics approval was required as ruled by the ethics committee of Shanghai sixth people's Hospital. Patient consents to the treatment protocol were obtained accordingly.

\section{Consent for publication}

Not applicable.

\section{Availability of data and materials}

The datasets used and/or analysed during the current study are available from the corresponding author on reasonable request.

\section{Competing interests}

The authors declare that they have no competing interests.

\section{Funding}


No funding was obtained for this study.

\section{Authors' contributions}

XLL: contributed to designing the study, revising the manuscript and performing of the index surgery. WN conducted the data analyses and drafted the manuscript. JQC, WW, YKG, CZ and WTJ contributed significantly to data analyses and the performance of the index surgery. All authors have read and approved the manuscript.

\section{Acknowledgements}

Not applicable.

\section{References}

1. Tzioupis C, Giannoudis PV. Prevalence of long-bone non-unions. Injury. 2007;38(Suppl 2):3-9.

2. LaVelle DG. Delayed union and non-union of fractures. In: Canale TS, editor. Campbell's operative orthopaedics. 9th edition. St Louis (MO); 1998. P. 25792629.

3. Giannoudis PV, Atkins R. Management of long-bone non-unions. Injury. 2007;38(Suppl):1-2.

4. Cunningham BP, Brazina S, Morshed S, Miclau T 3rd. Fracture healing: A review of clinical, imaging and laboratory diagnostic options. Injury. 2017;48(Suppl 1):69-75.

5. Arrington ED, Smith WJ, Chambers HG, Bucknell AL, Davino NA. Complications of iliac crest bone graft harvesting. Clin Orthop Relat Res. 1996;329:3009.

6. Roldán JC, Jepsen S, Miller J, Freitag S, Terheyden H. Bone formation in the presence of platelet-rich plasma versus bone morphogenetic protein-7. Bone. 2004;34:80-90.

7. van Bergen CJ, Kerkhoffs GM, Özdemir M, Korstjens CM, Everts V, van Ruijven LJ, et al. Demineralized bone matrix and platelet-rich plasma do not improve healing of osteochondral defects of the talus: an experimental goat study. Osteoarthritis Cartilage. 2013;21(11):1746-54.

8. De Long WG Jr, Einhorn TA, Koval K, McKee M, Smith W, Sanders R, et al. Bone grafts and bone graft substitutes in orthopaedic trauma surgery. A critical analysis. J Bone Joint Surg Am. 2007 Mar;89(3):649-58.

9. Marx RE. Platelet-rich plasma (PRP): what is PRP and what is not PRP? Implant Dent. 2001;10(4):225-8.

10. Marx RE, Carlson ER, Eichstaedt RM, Schimmele SR, Strauss JE, Georgeff KR. Platelet-rich plasma: growth factor enhancement for bone grafts. Oral Surg Oral Med Oral Pathol Oral Radiol Endod. 1998 Jun;85:638-46.

11. Kanthan SR, Kavitha G, Addi S, Choon DS, Kamarul T. Platelet-rich plasma (PRP) enhances bone healing in non-united critical-sized defects: a preliminary study involving rabbit models. Injury. 2011 Aug;42(8):782-9.

12. Gruskin E, Doll BA, Futrell FW, Schmitz JP, Hollinger JO. Demineralized bone matrix in bone repair: history and use. Adv Drug Deliv Rev. $2012 ; 64: 1063-77$.

13. Ziran BH, Smith WR, Morgan SJ. Use of calcium-based demineralized bone matrix/allograft for non-unions and posttraumatic reconstruction of the appendicular skeleton: preliminary results and complications. J Trauma. 2007;63:1324-8.

14. Wilkins RM, Kelly CM. The effect of allomatrix injectable putty on the outcome of long bone applications. Orthopedics. 2003 May;26(suppl 5):s567-70.

15. Han B, Woodell-May J, Ponticiello M, Yang Z, Nimni M. The effect of thrombin activation of platelet-rich plasma on demineralized bone matrix osteoinductivity. J Bone Joint Surg Am. 2009 Jun;91(6):1459-70.

16. Ilgenli T, Dündar N, Kal BI. Demineralized freeze-dried bone allograft and platelet-rich plasma vs platelet-rich plasma alone in infrabony defects: a clinical and radiographic evaluation. Clin Oral Investig. 2007;11(1):51-9.

17. United States Food and Drug Administration (USFDA). Office of Device Evaluation. Guidance Document for Industry and CDRH Staff for the Preparation of Investigational Device Exemptions and Premarket Approval Application for Bone Growth Stimulator Devices, 1988.

18. Hierholzer C, Sama D, Toro JB, Peterson M, Helfet DL. Plate fixation of ununited humeral shaft fractures: effect of type of bone graft on healing. J Bone Joint Surg Am. 2006;88(7):1442-7.

\section{Figures}



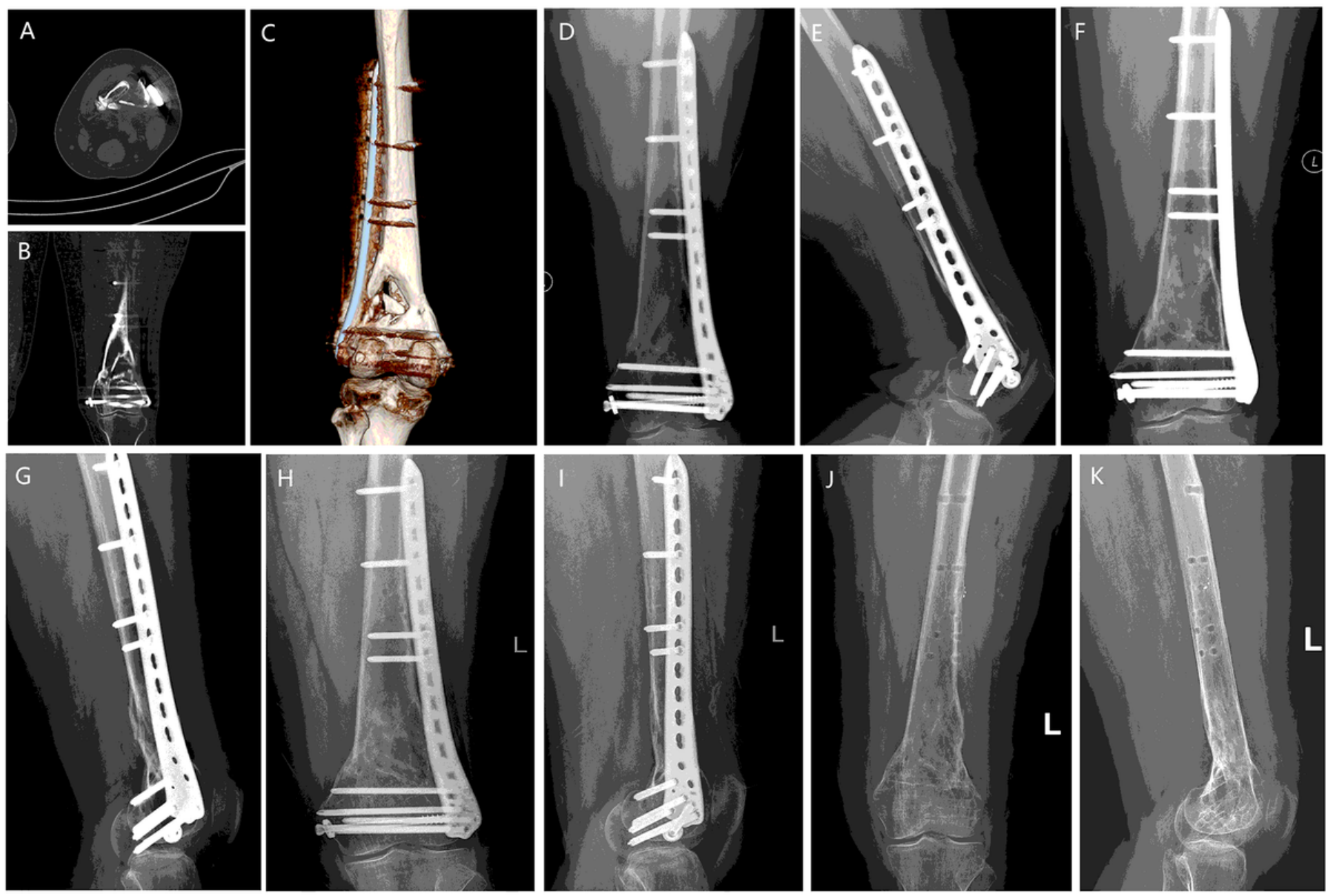

Figure 1

The CT scans (A, B, C) and the preoperative X-ray films (D, E) identified the nonunion of femoral supracondyle. The Judet decortication technique was used to expose the nonunion sites, and the paste comprised of DMB, PRP and allograft was implanted to fill the bone defect, covered with allogenous cortical bone around. Postoperative anteroposterior (F) and lateral (G) position films of X-ray were taken 3 days after surgery. The follow-up radiographic image showed bony union was achieved at 6 months $(\mathrm{H}, \mathrm{I})$. The hardware was removed 16 months postoperatively $(\mathrm{J}, \mathrm{K})$. 


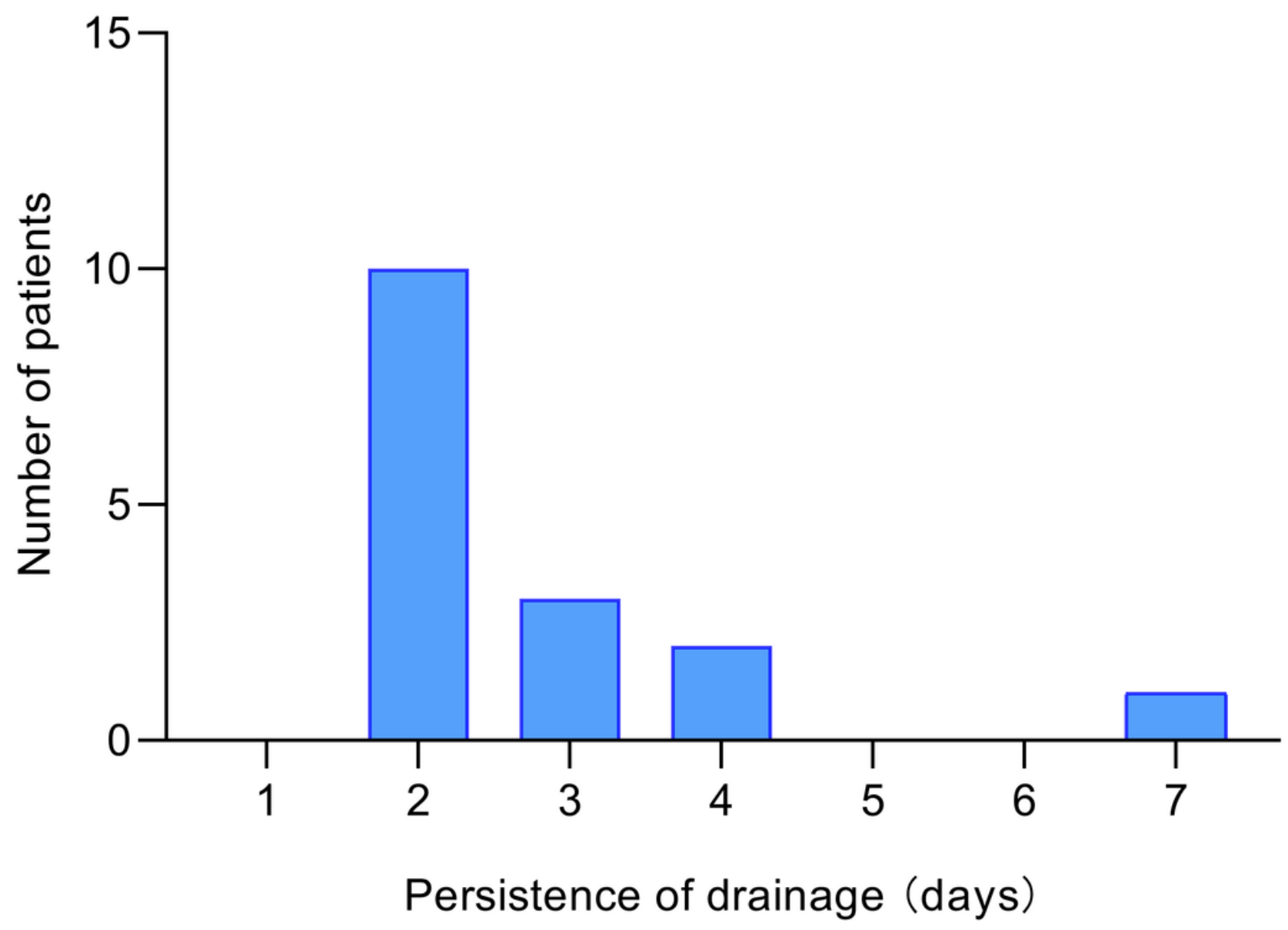

Figure 2

Column chart showing the situation of postoperative drainage persistence. 


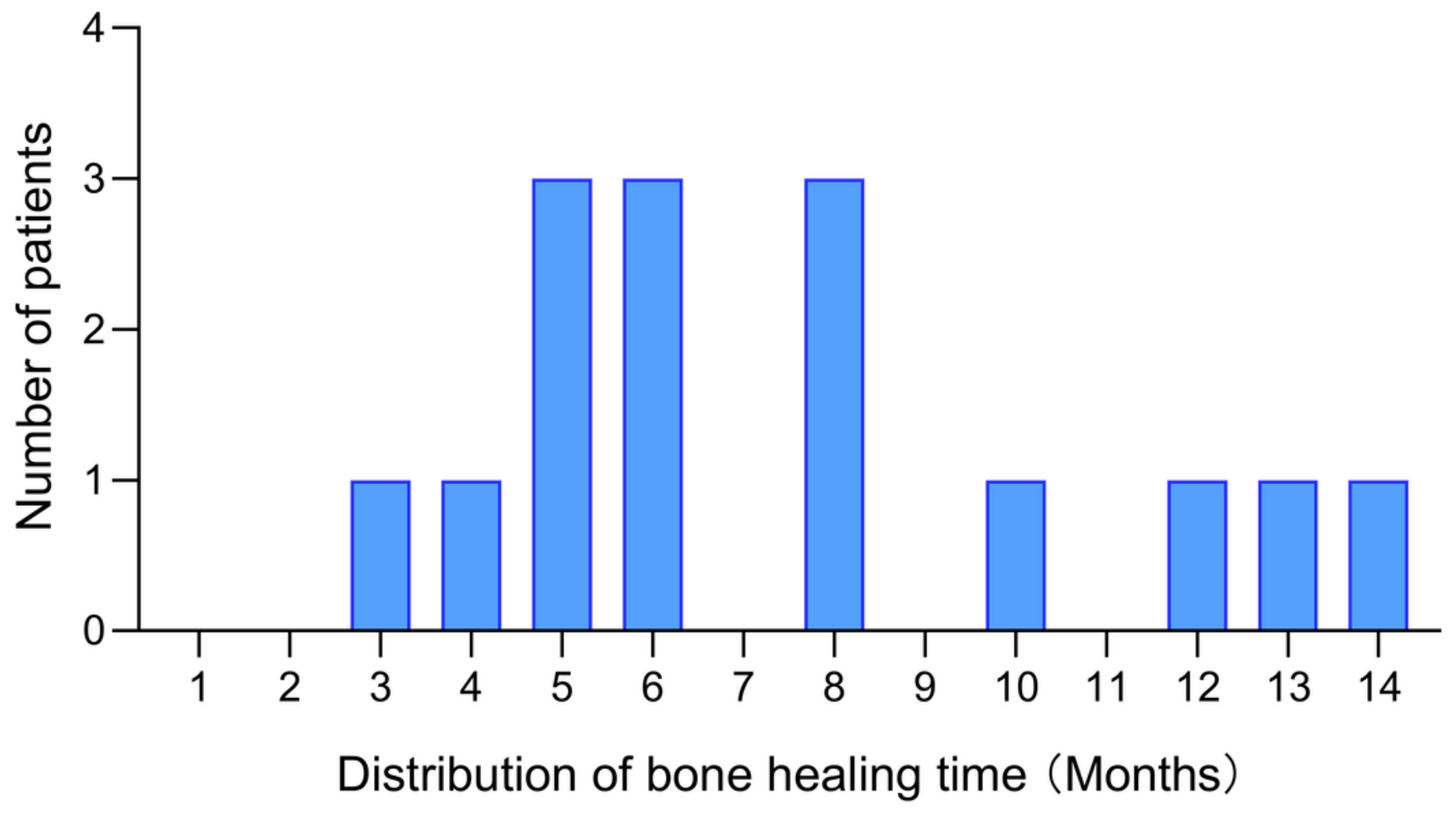

Figure 3

Column chart outlining the distribution of bone healing time (15 patients; mean time: 7.5 months). 